\title{
Entre las musas y la espada: La imagen del artista durante el primer franquismo
}

\author{
Raquel Pelta Resano*
}

\begin{abstract}
RESUMEN
ABSTRACT

El propósito de este trabajo es hacer un breve recorrido por los distintos textos que la literatura artística del primer franquismo dedicó a la figura

del artista. Escritores, críticos y periodistas insistieron en una imagen tópica, procedente del Romanticismo, a la que se despojó de todo contenido revolucionario o antisocial y sobre la que se añadieron elementos de corte exacerbadamente nacionalista $y$ católico. Hubo, además, ciertos sectores que trataron de convertir al artista en instrumento de propaganda politica y reclamaron su compromiso con los valores del régimen de Franco.

The aim of this article is to explore the image of artist present in several writings published during the early regime of the General Franco. Writers, critics and journalists stressed a commonplace image, stripped of any revolutionary or antisocial root. Some radical nationalist and catholic elements were added to this image. Besides, some theorists claimed to artist's political compromise for the construction of the new state.
\end{abstract}

* Tercer Ciclo. Departamento de Historia del Arte. UNED. 
"Uno de los más punzantes problemas que se encuentra planteado de antemano la España que renace es el que apunta a lo que ha de ser su arte. Las nuevas falanges hispánicas, revolucionarias y tradicionales a un mismo tiempo, han aprendido pronto algo que la agonizante clase burguesa no llegó a saber nunca bien: que el arte es esencial para el Estado.

[...] el arte, como la ciencia especialmente cuando poseen una profunda significación social, colectiva, nacional, extraen sus ideas del sentido de la vida, de la actitud ante el mundo, de la fe eucarística o del descreimiento último. El artista y el hombre de ciencia no captan la pura objetividad de las cosas, sino que encuentran siempre, precisamente lo que iban buscando, guiados por una oculta, intima, demoníaca o divina luz" '.

Efectivamente, Falange, Franco y el resto de los sectores que compusieron el mapa político del régimen del 18 de julio, siempre fueron conscientes de que el arte era "esencial para el Estado", como lo demuestra la instrumentalización que del mismo hicieron, especialmente a partir de la década de los cincuenta; pero pese a lo que pueda hacernos suponer la rotundidad de las frases que abren este artículo, escritas por un jovencísimo José Luis López Aranguren y publicadas en la revista Vértice en 1937, la "España que renace" nunca resolvió tan "punzante» problema, porque, de la misma manera que nunca hubo un arte franquista de caracteristicas propias, tampoco el franquismo fue capaz de elaborar una teoría artística mínimamente coherente ${ }^{2}$, aunque, desde luego, no podamos pasar por alto algún que otro intento, llevado a cabo durante los primeros años de la postguerra, procedente de los sectores falangistas más "avanzados».

Quizá pueda hallarse alguna explicación si tenemos en cuenta que, tal y como indica Julio Aróstegui, hablando de la naturaleza del franquismo: «El régimen de Franco no es en forma alguna el «episodio español» del fascismo, o no se limita a ello en forma alguna. Cuestión distinta que sería disparatado ignorar, es la de que la trayectoria primitiva del Régimen haya estado ligado a las vicisitudes de la historia exterior y entre ellas centralmente con el propio fascismo. La verdad del franquismo, su médula constitutiva, es el proyecto de restauración con sus rasgos estructurales más profundos de una España muy antigua, la de la dominación del mundo

José Luis Lopez Aranguren: “El arte de la España Nueva”, Vértice n 5, septiembre-octubre de 1937

Fundamental para estas cuestiones es la consulta de la tesis doctoral de Angel LIORENI: HERnANDEZ, Arte e ideologia en la España de ia postguerra (1939-1951). Universidad Complutense de Madrid, 1992, o el libro publicado a partir de la misma titulado Arte e ideologia en el franquismo (1936-1951), Madrid, Visor, Col. La Balsa de la Medusa, 1995. 
agrario, proyecto que se sirvió de un aparato de poder que so capa de modernidad -y éste es el rasgo fascista- representó, sin embargo, la pervivencia de un arcaísmo que se veía a sí mismo como un Estado de derecho cristiano clásico $[\ldots]{ }^{3}{ }^{3}$.

Tras una primera lucha entre quienes aspiraban a un Estado fascista y quienes lo hacían a un Estado católico, los modelos políticos franquistas estuvieron enraizados en la línea del tradicionalismo del siglo XIX, aunque el disfraz falangista sirviera de coartada en los primeros tiempos y realizara ciertas aportaciones. $Y$, de esta manera, si los ideólogos del régimen insistieron en el "pensamiento clásico» español del Siglo de Oro y de la Contrarreforma ${ }^{4}$, los teóricos del arte lo hicieron en la pintura de Vélazquez, Zurbarán, Murillo, Ribera y El Greco, por ejemplo, y en la arquitectura de Herrera; todos ellos artistas que, por otra parte, nunca habian dejado de servir de referencia y que, especialmente con la Generación del 98 , se habian convertido en todo un símbolo. Ahora, serán, además, estandarte de una etapa imperial grandiosa, plena de catolicidad, que se soñaba repetir.

Un Estado así, con una ideología política y social de Antiguo Régimen no podía dar lugar, desde luego, a planteamientos artísticos muy novedosos y si, en un principio, hubo quienes propusieron un arte al servicio de las ideas del "Nuevo Estado" - lo que no quiere decir que apostaran por un arte de vanguardia (por supuesto, nada más lejos de la realidad), ni que fueran menos reaccionarios - también existieron aquellos que, siendo mayoría, defendieron y, finalmente, impusieron el academicismo más rancio; un academicismo que, por otra parte, nunca había abandonado su lugar de preeminencia ni aún en los años republicanos.

Sin una teoría estética definida, poco se podía esperar de quienes andaban empeñados en trazar el papel que ese artista "guiado por una oculta, íntima, demoníaca o divina luz", como nos dice Aranguren, habria de desempeñar en la configuración de un arte que respondiera a las nuevas circunstancias. Puede decirse que sobre ese artífice -que algunos hubieran querido mitad monje, mitad soldado- sólo se produjeron especulaciones vagas, divagaciones no demasiado originales que en numerosas ocasiones retomaban ideas ya presentes en el aire desde tiempos remotos, y que nunca se concretaron en ninguna dirección precisa y clara.

Julio AROSTEGUI, "Opresión y pseudo-juricidad. De nuevo sobre la naturaleza del franquismo", en Bulletin d'Histoire Contemporaine de l'Espagne, $n^{\circ} 24$, diciembre de 1996, Centre National de la Recherche Scientifique, Bordeaux. Francia, 1996, págs. 37-38.

Ibidem, pág. 38. 
Si exceptuamos el conocido texto de Ernesto Giménez Caballero El Arte y el Estado, - hay que recordar que fue escrito antes de la Guerra Civil-, prácticamente no existieron obras fundamentales sobre el tema. Los teóricos, con afanes doctrinarios, esparcieron sus ideas a través de artículos aparecidos en publicaciones ligadas, en su mayoría, a los círculos falangistas y que vieron la luz durante los primeros años del régimen, especialmente antes del descalabro de las potencias del Eje en 1945.

Lejos ya de las especulaciones más "novedosas" -por denominarlas de alguna manera-, y de forma paralela a éstas, se escribieron también un buen número de biografías de artista, entrevistas y críticas de arte, que redundaron en una imagen popular perfilada en el Renacimiento, forjada en el Romanticismo, pasada por el tamiz burgués y difundida a través de la novela y la critica desde finales del siglo XIX ${ }^{5}$; una imagen que lo convertia en un ser neurótico, enfermo, sacrificado e hipersensible.

En este punto, sin duda, habría que recordar además que, como ha indicado Ignacio Henares, ya nuestros críticos románticos perfectamente incardinados en el proceso de constitución de una ideología burguesa, se impusieron «la obligación de aclarar que la nueva estética nada tiene que ver con la filosofía del desencanto; prorrogando la crítica antiiluminista de finales del Setecientos, no asumirá por su carácter resueltamente "social" los aspectos patológicos de los stürmer: dar cabida al sentimiento no significa caer en la desesperación. Hay como un restablecimiento de la armonía leibniziana: la defensa de la moral y la religión constituye un correctivo histórico" ${ }^{6}$, lo que sin duda contribuyó a una visión española del genio artístico bastante atemperada, que se prolongará hasta nuestro siglo y no será incompatible con la ideología de los sectores políticos y sociales más conservadores que apoyaron al régimen de Franco.

Porque, - dejando a un lado, por ahora, los escritos que hablan de un ser cuya misión no es otra sino la de ensalzar a los vencedores de nuestra Guerra Civil y transmitir sus valores-, si hacemos un recorrido por los textos que circularon entre los lectores españoles de los años cuarenta y principios de los cincuenta, nos encontraremos a un artista descrito bajo

5 Al respecto, pueden consultarse los articulos de Sagrario Aznar ALMAZAN, "Románticos y románticos. La imagen del artista contemporáneo a través de los cuentos del Blanco y Negro". Actas del $X$ Congreso del CEHA. Los clasicismos en el arte español, Madrid, UNED, Dpto. de Historia del Arte, 1994, pág. 85 y ss., y "La Quimera", Espacio, Tiempo y Forma, Madrid, UNED, Serie VIIV, $\mathrm{n}^{0} 7,1994$, además del libro de Francisco Calvo SerRaller La novela del Artista. Madrid, Mondadori, 1990.

Ignacio Henares, con la colaboración de Juan Calatrava, Romanticismo y Teoria del Arte en España, Madrid, Ediciones Cátedra, S.A., 1982. 
algunas de las características más tópicas, superficiales y llamativas del Romanticismo; un artista de imagen tergiversada que lo sitúa dentro de una dimensión tragicómica y espectacular, en el sentido estricto de espectáculo público, de rareza o de divertimento social, aunque todo ello no deje de cubrirse con un manto de grandilocuencia retórica y un barniz de seriedad como correspondia a una España que se autoproclamaba defensora de los "valores eternos".

Así, a menudo, se resaltó la misantropía, el irresistible impulso a la introspección y el carácter raro, excéntrico, reflejado no tanto en un comportamiento antisocial -impropio para la sociedad española del franquismo- como en la incapacidad de hacer frente a la vida cotidiana de manera práctica. Desde luego, siempre habrá grados de excentricidad y en algunos artistas se resaltarán más que en otros. En ese sentido, Solana y María Blanchard serán, a los ojos de sus biógrafos, dos paradigmas perfectos. Del primero no dejará de subrayarse su afición a coleccionar maniquíes, carátulas, autómatas, momias y animales disecados, ni su preferencia por "reunirse con los compañeros más desequilibrados de la Escuela, para beber por las tascas y colmados» ${ }^{7}$, ni faltará la mención a otra de sus actividades, al parecer habituales: "obediente a oscuros instintos, sigue los entierros que se dirigen a los antiguos camposantos" ${ }^{8}$. A Maria Blanchard, la condesa del Campo de Alange se refiere en estos términos: "Todo lo absurdo cabe en ella, a veces después de una acalorada e interminable discusión, en la que parecia poner toda su alma, da repentinamente la razón de buena voluntad y pasa a otro asunto sin darle la menor importancia. Pone azúcar en la sopa, empieza los libros por el fin y va al mercado en taxi para ahorrar dos francos en la compra. [...].

[...] Esta mujer genial, llena de fuertes contrastes como su pintura, tiene una psicología tan curiosa que ella misma es su mejor cuadro" " .

La excentricidad presentada en su grado sumo nos llevaría, por supuesto, a otro de los elementos habituales en las vidas de artista, que tampoco faltará de una buena parte de las escritas durante la postguerra: la locura como patología propia del genio, algo que nos remonta, nuevamente, al siglo $x \mid x$, aunque en este caso la herencia que recogerá y no olvidará el xx sea la que ya entonces se perfiló como alejada de la mirada romántica que nos hablaba de un "profeta-artista" y, por el contrario, se

Emiliano M. Agultera, José Gutiérrez Solana. Aspectos de su vida, su obra y su arte. Barcelona, Editorial Iberia, S.A., 1947, pág. 11

Ibidem, pág. 12

Condesa del Campo de Alangit. Maria Blanchard, Madrid, Hauser y Menet, 1944, pág. 73. 
aproximaba más a "un camino material-positivista que quiere entender al genio como cantidad mensurable y físicamente determinable" ${ }^{10}$. Nos encontramos, pues, con el ya viejo deseo de hallar una explicación científica a la creación que vaya más allá de la filosofía, para lo que se buscará un factor físico que explique la actividad artística o influya en ella; es, una vez más, el eco de las patografías de Lélut, Lombroso, Moreau de Tours, por sólo citar a unos cuantos autores. Una locura que ahora, filtrada por el espíritu burgués-conservador se ha transformado para la gran mayoría del público en un símbolo de genial anormalidad, si el artista encaja dentro de sus gustos, o en una lacra, en un factor de descalificación, si el artista se sale de ellos.

Solana vuelve a ser un buen ejemplo, porque tal y como lo presentan sus biógrafos encarna las dos caras de esa moneda: «Del Greco suele decirse que fue un loco. O, cuando menos, un paranoico. Otro tanto se viene diciendo de un sinnúmero de insignes artistas. $Y$, desde luego, eso mismo se ha dicho y se dice, de José Gutiérrez-Solana".

Quienes años atrás, combatían sañudamente a nuestro pintor, gritábanlo así. Ajenos, realmente, a la significación que pudieran tener tales opiniones. Y, luego, los amigos y los admiradores de Solana se lo dirán unos a otros también, pero un poco sotto vocce: como si la locura, o la paranoia, fuese algo vergonzoso y temiesen, al juzgar así, ofender al artista [...] cual si entendieran - sin entender realmente- que, por ser pintura de un paranoico, es menos estimable la pintura de Solana. [...]

[...] Cuando la locura se manifiesta así, hay que felicitarse de que se dé esta especie de locos y... comprobar tal locura" ${ }^{11}$.

Pero a pesar de que en este caso el autor del texto, Emiliano Aguilera, considere la enfermedad mental como fuente de genialidad, no dejará de intentar explicarnos su origen sin perder de vista las especulaciones cientifistas sobre la transmisión hereditaria, que fueron habituales en la literatura médico-artística desde mediados del xIx. De esta manera, esa supuesta locura de Solana se debe a: “la consanguinidad de los padres del pintor [...] revolviendo y confundiendo posos hereditarios", "la madre murió loca y el padre era, sin duda, un solitario. Habia en él, además,

Eckhard NEuMANN. Mitos de artista. Estudio psicohistórico sobre la creatividad. Madrid Editorial Tecnos. S.A., 1992, pág. 129.

Menciones a la supuesta locura de Solana aparecieron. tratadas más o menos de pasada en las obras de Cecilio Barberzan: Gutiérrez-Solana. Ediciones de Arte Urgano, Madrid, 1933 Ramón Gom ? of I A Stana, José Gutiérrez-Solana. Editorial Poseidón, Buenos Aires, 1944. -que trato la cuestión de manera frivola-- y Manuel Sanche/ CAMAHco. Solana, Madrid, 1945. 
mezcla de razas y es hijo de un hombre que, casado en América, procedia de un país lejano» y..., "los familiares locos son varios» ${ }^{12}$.

Sin salir del terreno de la patografía, otro de los temas preferidos de los críticos e historiadores españoles fueron las anomalías, los dolores físi$\cos y$, en definitiva, las enfermedades, que siempre constituyeron una característica importante del alma romántica y se consideraron signo de personalidad genial. Hubo, pues, complacencia en mostrarnos a un artista que sufría y que proyectaba su dolencia en la obra, superándola a través de ésta o convirtiéndola en su reflejo. Como en escritos de otras épocas, se nos está hablando de la compensación gracias a una energía poco común que permite al artista superar la prisión que le impone la naturaleza. Algunos ejemplos: Goya, «sus delirios de enfermo; sus ensueños de hombre que es presa de la fiebre, dejan en él una hondisima huella» ${ }^{13}$, 10 que explicaría la realización de Los Caprichos y Los Sueños; Rosales: "La misma enfermedad que mina y destroza la naturaleza de nuestro pintor, la tuberculosis, es cual un signo de romanticismo, creadora - sin duda - de una espiritualidad de interesantes acentos; fiebre de los sentimientos, paroxismo de la voluntad creadora, hoguera infernal que consume y que purifica mientras se afirma esplendorosamente la vida de la imaginación» ${ }^{14}$; José Villalba Muñoz: "Toda su vida habría de ser un hombre delicado, de aspecto enfermizo, seco de carnes, cargado de espaldas. [...] Pero en sus ojos, pequeños y ávidos, había esa luz que sólo tienen los hombres excepcionales» ${ }^{15}$; María Blanchard: “Desde sus primeros pasos María se revela deforme. Tiene, por tanto, la infancia melancólica de los niños débiles y enfermos» ${ }^{16}$ o Vayreda: “Acaso su misma enfermedad volvíale suave, ya que Vayreda padeció del corazón. Del mismo modo que la sutil delicadeza en la obra de Rafael, Watteau, Mozart o Keats se ha intentado explicar por la tuberculosis que padecieron, la substancial delicadeza en la obra de Vayreda, ¿pudiera acaso explicarse por la enfermedad cardiaca que desde muy joven había soportado con melancolia y que llevó al maestro súbita y prematuramente a la tumba?" ${ }^{17}$.

\footnotetext{
Emiliano M. Actill E.rA, op. cit, 1947, págs. 27-28.

Ignacio dt. Br.ryrs. La vida y los cuadros de Goya. Barcelona. Iberia-Joaquín Gil, editores, s.f. pág. 14

Emiliano Aciun I ha. Eduardo Rosales. Su vida. su obra y su arte. Barcelona, Ibéria-Joaquín Gil, 1947. pág. 8 .

Antonio JiMlne z-LANo1. "Un pintor de! 98: José Villalba Muñoz". Arte Español, tercer trimestre de 1943. pág. 26.

Condesa del CAMPO de. Al. ANGe, op. cit., pág. 25

1943, pág. 30
} 
Junto a estos textos circularon -desconozco con qué fortuna- libros como el titulado El dolor en la Vida y en el Arte (Ensayos médico-biográficos sobre tuberculosos célebres) del doctor Cortejoso que darían el respaldo científico a las especulaciones literarias ${ }^{18}$.

$Y$ es que el dolor, también en los años cuarenta, sera condición sine qua non de la vida del genio, especialmente del que vivió en el pasado. En ese sentido, todos los tópicos se dieron cita. Por una parte, porque gracias a una especial sensibilidad, el artista sufre más que los demás. Por otra, porque las circunstancias externas le son adversas. Ha de luchar, por ejemplo, contra el rechazo de la amada o la ausencia completa del amor, la escasez de recursos económicos y el hambre, la muerte de los seres queridos, la envidia o la estrechez de miras de sus colegas profesionales. Ni el mismo Velázquez puede escapar a esta caracterización del genio, porque en la biografía escrita por Rafael Benet ${ }^{19}$ se insiste en la anécdota de quienes celosos del arte del pintor sevillano le dicen a Felipe IV que éste sólo sabe pintar una cabeza. Por supuesto, no faltará tampoco la alusión a la incomprensión por parte del público y en esta ocasión soportada heróicamente no sólo por el artista ya desaparecido, sino también por el contemporáneo. Veamos, como ejemplo, el comentario que, en una monografía dedicada a Benjamín Palencia, hace Ramón Faraldo sobre el Madrid de postguerra: «El pintor debe convertirse en un lamentable sujeto social, sin otra misión que halagar a una clientela impertinente y despótica, que lo que querría, en suma, es pintar ella, pintarse ella como ella se ve. El dinero se gana con facilidad, y, entre los dividendos de aluvión, queda a menudo algo para subastar la dignidad de los artistas" 20. De nuevo vamos a encontrarnos con esos "filisteos" de los que tanto hablaron Clemens von Brentano y Thomas Carlyle. En este caso, Faraldo está describiéndonos lo que fue una situación real, que afectaría al protagonista de su libro hasta cierto punto ${ }^{21}$, pero la mayoría de los autores del momento subrayaron la fractura existente entre el genio creador y una sociedad poco interesada en las aventuras del arte en un instante en el que esa irreparable distancia era auténtica pero no precisamente para la mayoría de los artistas biografiados por ellos, sino para muchos otros que

\footnotetext{
Fue editado por la Editorial Iberia de Barcelona en 1943, y en él se contiene una biografia de Rosales.

Rafael Benet, Velázquez. La actualidad de Velázquez, Barcelona, Iberia-Joaquín Gil Editores, S.A., 1946.

Ramón FARALDO, Benjamín Palencia, Barcelona, Galerías Layetanas, Imp. S.A.D.A.G., 1949. págs. 42-43.

Palencia venia recibiendo la atención y el respeto de la crítica desde 1940 y fue junto a Cossio uno de los pintores preferidos por los intelectuales falangistas.
} 
por su compromiso con la vanguardia fueron condenados a una auténtica marginación de la que sólo saldrán - siempre hablando en términos relativos- cuando, convertidos en instrumentos políticos del Estado, sirvan de embajadores de una pretendida modernidad -más ficticia que realen la década de los cincuenta. En fin, una pose cínicamente burguesa por parte de los críticos; eso sí, bastante estética.

Más estética todavía resulta otra imagen que, evidentemente, no podía faltar en toda buena mitologización del genio: la del artista inspirado. Como en otros tiempos, el don de la inspiración y el talento innato serán los elementos irracionales que sirvan para explicar la creación artística porque "sin la intervención del espíritu no existe la obra de arte" ${ }^{22}$. Este interés por resaltar el papel de esos elementos es de signo inequívocamerite romántico, aunque no se va a entender como en sus orígenes, en el sentido de una ampliación de la facultad kantiana del Juicio, sino más bien como un rechazo de lo racional o, más exactamente, del componente intelectual en el arte. Es algo que estaba presente a finales del ochocientos pero que ahora, es el reflejo de una sociedad dominada por la Iglesia e impregnada de algunas de las concepciones del fascismo español donde "la función del político es religiosa y poética» y donde «la masa tiene que seguir a sus jefes como a profetas" ${ }^{23}$. Y es que Falange si bien no fue, como ha indicado Rafael Águila Tejerina, "un irracionalismo a secas" ${ }^{24}$, sí otorgó un importante papel a los aspectos emocionales del individuo. Denostar lo racional fue la consecuencia lógica del desprecio con que fueron tratados los intelectuales - acusados, en numerosas ocasiones, de haber conducido al pueblo español a la catástrofe que culminó en la Guerra Civil-: «ni Unamuno, ni Ortega -ni, claro es, todos nuestros intelectuales- vale lo que un rapaz rabioso de veinte años fanatizado por su pasión española» ${ }^{25}$.

Pero, volviendo a la inspiración, se produjeron un buen número de escritos que nos presentan a un artista arrebatado, fuera de sí, bajo el furor divino... Un artículo de Azorín titulado "Cuento a medio hacer» nos lo describe de la siguiente manera: "te he visto a ti en los preliminares del cuadro, ibas y venías desasosegado, pronunciabas palabras sin saber que

\footnotetext{
Rafael BENET, op. cit., 1946, pág. 17.

José Antonio Primo de RIVERA: “Homenaje y reproche a don José Ortega y Gasset", Haz, n̊ 12, 5-XII-35, pág. 1, citado por Rafael Águila Tejerina en Ideología y fascismo, Madrid, Centro de Estudios Constitucionales, 1982, pág. 169

Rafael ÁGuila TEJerina, op. cit, pág. 161.

Bravo Martinez, Historia de la FE de las JONS, Ed. Nacional, Madrid, 1940, pág. 218, citado por Rafael Águlla Tejerina, op, cit., pág. 169.
} 
las pronunciabas, has hecho vario dibujo (sic) al carbón; quien te viera sin conocerte diría que estabas enajenado. Y diría la verdad; no eras tuyo, eras de alguien ajeno a ti. En suma, te dominaba una fuerza: la fuerza creadora; yo estaba contemplando, en parte la gestación de tu obra; digo en parte, porque allá dentro de ti mismo, ¿quién podría escudriñar?" 26 . Esa "fuerza creadora», a la que se refiere el escritor, es para el periodista Emiliano Aguado: "una voz que nos llega de lo alto derramada en cánticos y transportes, como una lluvia de ternura y de tibieza que nos penetra y colma de gratitud", y se puede conseguir siguiendo "los mismos caminos que para conseguir las cosas más difíciles de la tierra [...]; en todo caso se trata siempre de invocar la ayuda de lo alto, preparándose como quien sabe que va a recibir un mensaje de Dios» 27 . Ese "efluvio sagrado» ${ }^{28}$ es, pues, una manifestación de la gracia divina, -no podía ser de otra manera en un país que proclamaba la vuelta a la tradición católica-, que para revelar "el misterio inescrutable del mundo y de la vida» utiliza a un "hombre inerme y casi enajenado", que: "No sabe lo que hace; en muchos casos ni siquiera es capaz de adivinar el rastro de luz y de tinieblas que va a dejar en el mundo como señal sagrada de su existencia» ${ }^{29}$. Y es "Que no hay comprensión artística sin revelación de Dios en las cosas; y para llegar a ella en la limitación de nuestro cuerpo mortal, sólo en casos muy excepcionales de Gracia se podrá hablar de joia directa y no de superación de angustia y, todavia, este llegar a la bienaventuranza por la angustia será siempre un súbito y excepcional estado de Gracia que no puede resistirse más allá de cinco o seis segundos. Jean Grenier, hablando de estas visiones del mundo estrechas y apasionadas, se refiere a Jaspers meditando sobre la filosofía de Kierkegaard y afirma que una experiencia intensa es mucho más lo absoluto que la totalidad racional de las experiencias» ${ }^{30}$.

El artista es, pues, un elegido de Dios y tiene, por tanto, una misión trascendente: "es un descubridor de mundos, que luego nos da en sus obras como si, a solas con su vocación y su destino, las hubiera conquistado para siempre» ${ }^{31}$. Es, al fin y al cabo, quien nos presta sus ojos para que podamos ver el mundo -platonismo, plotinismo y Romanticismo, nuevamente-.

Azorín, "Cuento a medio hacer", Santo y Seña, Madrid, 5 de octubre de 1941

Emiliano Aguado, El arte como revelación, Madrid, Espasa Calpe, 1942, págs. 114- 115.

Ibidem, pág. 115

Ibidem, pág. 116

Rafael BENEt, op.cit., 1946, pág. 16.

Emiliano AGUADO, op.cit. pág. 101 
Claro que, a los críticos y biógrafos no todos los artistas les parecieron tan vinculados a la divinidad, sobre todo si se trataba de aquellos que habían estado o estaban relacionados con el arte de vanguardia, porque si bien en nuestro país no existió una prohibición expresa de aquellas manifestaciones artísticas que no concordaran con las oficialmente preferidas - que solían situarse en las esferas del realismo académico-, sí se produjeron continuos ataques a ellas. Las vanguardias eran responsables de la decadencia y crisis del arte contemporáneo, de la pérdida de la identidad nacional gracias a un internacionalismo que acababa con las peculiaridades artísticas de cada país - argumento característico del nacionalismo exacerbado del régimen-; fueron tachadas de mero juego y juzgadas como "causantes de la deshumanización del arte con la consiguiente separación entre arte y vida" ${ }^{32}$-evidente reinterpretación de las ideas orteguianas-; una y otra vez se presentaron como un fenómeno de modas -ya pasado y muerto, propio de un liberalismo que tenía los días contados- que ponían el arte en manos de los comerciantes internacionales.

Tampoco estas ideas eran nada nuevo. Simplemente, coincidian con las de quienes desde siempre se habian llevado las manos a la cabeza ante unos ismos que ponían en peligro los conceptos tradicionales del arte y la sociedad; unas ideas con las que los artistas más asentados comulgaban porque los nuevos estilos habían comenzado a amenazar una descansada posición que no estaban dispuestos a abandonar fácilmente.

Por otra parte, esa aversión a los ismos es comprensible si tenemos en cuenta que las ideas de Falange daban soporte intelectual al régimen. La concepción fascista del mundo pretendía la existencia de un sistema de valores de validez permanente que estructuraban el mundo. La rápida sucesión de movimientos artísticos iba en contra de la esencia misma de esa inmutabilidad, poniéndola continuamente en cuestión.

Bajo esa visión deformada, ¿cuál fue la imagen que se difundió del artista de vanguardia?

Como respuesta a esta cuestión podemos recurrir a las preguritas que la Condesa del Campo de Alarge plantea en la introducción a su libro sobre María Blanchard; todo un retrato de la colección de tópicos negativos ligados al artista moderno, que habían calado en la mentalidad del público, y de los que la autora se hace eco, aunque lo haga precisamente para proceder a su defensa: "Ante la pintura moderna la gente experi-

Ángel Llorente, Arte e ideologia en el tranquismo (1936-1951), Madrid. Visor, Col. La Balsa de la Medusa, 1995, pág. 44. 
menta un sentimiento de malestar, y desorientados se preguntan ¿qué quieren decirnos los pintores de nuestros días? ¿por qué no nos cuentan fábulas o historias como teníamos costumbre, páginas del Antiguo o del Nuevo Testamento, leyendas mitológicas o espectaculares batallas? ¿por qué nos presentan en su lugar cuadros sin asunto, en que personajes insignificantes son extrañamente deformados? ¿y esos pintores llamados cubistas en cuyas composiciones geométricas apenas se adivina el rastro de la naturaleza o de la especie humana?, ¿no serán esos artistas de vanguardia unos desaprensivos que, dirigidos por los negociantes judios y movidos por medio de una hábil propaganda, estén explotando a los honrados burgueses, a los confiados millonarios? $Y$ esos espectadores del arte moderno añaden todavia: Esa pintura no puede ser sincera ${ }^{33}$.

Desaprensivos, insinceros..., a tenor de lo que de ellos se dijo, nuestros vanguardistas fueron, al menos hasta 1951 -momento de la I Bienal Hispanoamericana de Arte que desató una considerable polémica- la antítesis del artista, porque éste podía ser «angélico o luciferino, según su emoción creadora de formas se incline hacia el Bien o hacia el Mal: hacia el Orden o el Caos, hacia lo Benigno o lo Monstruoso, hacia la Forma o la pura Materia sin deseos de intormarse» ${ }^{34} \mathrm{y}$, desde luego, parece que los creadores más avanzados debieron de pertenecer al segundo tipo.

A menudo se les presentó como personajes vanidosos, extravagantes, arbitrarios, desquiciados, absurdos, rebuscados, que realizaban su obra no de una manera pura, al «impulso de sus facultades y de su ideología», sino con «una preconcebida picardía de causar el asombro a otra persona, desconcertándola en un terreno en el que no se atreve a discutir, por temor a ser tachada de ignorante" ${ }^{35}$, que trabajaban al dictado de "exotismos premeditados y no sentidos" ${ }^{36}$.

Sólo el «impulso» es auténtico. Frente a él, el componente racional es signo de falsedad. Por ello, su intervención en la creación es un elemento más para la descalificación del artista - nuevamente volvemos a encontrarnos con el desdén por el factor intelectual, del que ya he hablado unas líneas más arriba_-, por ejemplo: "Desde 1912 a 1930, los artistas expresionistas [...] Reniegan de la razón y de cualquier intelectualismo, pero más bien presumen de ello, pues en su trabajo demuestran todo

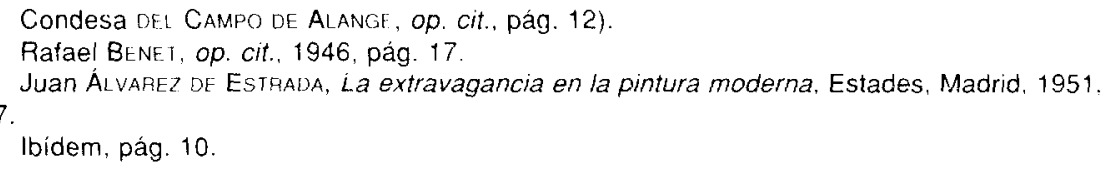


lo contrario, dejando constancia de haber intervenido una tenebrosa literatura cerebral ${ }^{37}$.

Los artistas modernos recibieron toda clase de insultos: unos relacionados con su capacidad creativa, su estado mental y su oficio, otros, eco de la arraigada creencia de que el arte moderno no era sino el invento de unos cuantos para conseguir dinero fácil y desconcertar al público, algunos más poniendo en relación, de manera claramente tendenciosa, orientación artística con inclinación política - justo cuando en España sólo era posible una opción política-. Una pequeña muestra pueden ser algunos de los violentos adjetivos y frases con los que José Francés obsequia a los artistas más avanzados, con motivo de la I Bienal Hispanoamericana de Arte: “impotentes", "tomapelistas", "deficientes mentales", "arrivistas y secuaces azuzados por la crítica insolvente", "titís y pekineses de apolillado vanguardismo"...${ }^{38}$.

En el desprecio absoluto del vanguardista llegará incluso a negársele la única recompensa que, a sus penurias y renuncias, siempre habia tenido el artista: la del paso a la historia, la de la inmortalidad. De Picasso, ya entonces líder mundial indiscutible, nos dirá Álvarez de Estrada: "La mayor habilidad de Picasso consiste en haberse burlado de los snobistas de las dos últimas generaciones. Lo que no es poco. Pero su arte, aunque tenga defensores incondicionales, pero sospechosos, cada día que pase, repito, tendrá menos consistencia como ocurrió con otros "ismos"» ${ }^{39}$. Es el precio que deben pagar estos artistas por su falsedad, por su falta de autenticidad emotiva - uno de los valores supremos desde el Romanticismo-, el justo castigo por haber obtenido recompensa económica y fama en la vida: "El artista que se vende, como mercancia en Ionja, dimite de la excelsa misión con que Dios lo puso en la tierra y la Patria le pide" ${ }^{40}$, porque, por supuesto, para poder venderse ha tenido que hacer concesiones sobre su pureza, burlándose pero también prostituyéndose no ya al burgués, sino, lo que es peor, a los "esnobistas", término altamente peyorativo con el que a menudo se aludía a los amantes del arte moderno.

Sin embargo, además del ataque directo, el desprecio y la ofensa, la literatura artística del primer franquismo empleó, en sus versiones negativas,

Ibidem. pag. 40

José FRANCHS, "Sobre la Bienal de Arte". La Vanguardia. Barcelona. 12 de agosto de 1951. texto recogido en Miguel Cabañas Bravo. Politica artistica del franquismo. Madrid. C.S.1.C.. 1996, págs. 297-299.

Juan Ál VAREZ DE ESIHADA, op. cit., págs.27-28.

Framis, "El arte como misión". ABC, 7 de noviembre de 1941, pág. 3 
buena parte de esos mismos rasgos tópicos que hemos visto servían para trazar la imagen ideal del artista; una postura que, por otra parte, venia adoptándose desde finales del siglo xix con personajes como el médico alemán Max Nordau al frente, y que no era más que la continuación de la ya vieja batalla moral contra la modernidad, en la que psiquiatría y medicina, en general, se habian dado la mano con el fin de legitimar las normas de comportamiento y los valores burgueses.

Será por ello, quizá, que Fernando Álvarez de Sotomayor en su arremetida -más bien en su pataleta- contra la I Bienal Hispanoamericana de Arte, recurre además de a todos los prejuicios al uso sobre el arte de vanguardia, a la locura como instrumento para desautorizar a los artistas modernos. $Y$ así, en una carta publicada en el diario Madrid el 8 de noviembre de 1951, con el título “¿Quiénes son los locos? y dirigida al presidente de la Sección Psiquiátrica del Colegio de Médicos de Madrid, viene a compararlos con enfermos mentales. Entre otras cosas el escrito decía asi:"Por un lado [nos encontramos], los que defendemos la tradición de las artes plásticas con los más elementales cánones de belleza y nobles oficios de pintar y modelar a base de realidades objetivas y subjetivas; $y$. por otro, los que pretenden una rápida liquidación con el pasado y la creación de un arte nuevo (que, por cierto, lleva cuarenta años de gestación) en el cua! quepan todos los mayores absurdos y fealdades, las más inauditas aberraciones y las más divertidas experiencias, a las que ponen titulares de arte subrrealista, abstracto, indaliano y cuantos otros puedan irse inventando, sin que hasta ahora haya podido apreciar el público "sencillo" otra cosa que un afán de sorprenderie con extravagancias y las más torpes ofensas a la estética y, a veces, a la moral.

Todo ello no parecia tener importancia alguna. Ustedes, señores psiquiatras, no perderán el sueño ni el apetito a pesar de su trato constante con enfermos mentales. "Cosa de locos!" dirán ustedes. Pero... ¿y si de improviso les dijeran que los que tienen razón son los locos y que los que deben ser encerrados son ustedes?". A esta carta de Sotomayor siguió un buen escándalo y la obligada consulta por parte de los periódicos a los psiquiatras españoles para que refrendaran si el pintor, y por entonces Director del Museo del Prado, estaba en lo cierto ${ }^{41}$.

Pero la locura no fue el único rasgo descalificador porque si hemos visto que para los artistas "elegidos de Dios", esa enajenación mental, la incapacidad para llevar una vida cotidiana normal, el tormento amoroso, la

Miguel Cakanasi recoge en la obra citada esta polémica 
enfermedad o la pobreza eran síntomas de una sensibilidad superior y de genio, para los que estaban fuera de la categoría, significan todo lo contrario: depravación y mal vivir. Álvarez de Estrada dibuja con estas palabras el retrato de Modigliani: "bohemio de última categoría, y por añadidura enfermo a consecuencia de sus vicios y privaciones, que, por otra parte, aunque sea esto muy vulgar, no sabe cómo pagar la casa en que ha de dormir ni dónde ha de encontrar el pan que lo alimente» ${ }^{42}$.

Por contraposición, uno de los hechos que más se resaltarán en las biografías de ciertos artistas, ya consagrados y acordes a los gustos del régimen, fue su abandono de la vida bohemia y, como consecuencia del mismo, la plenitud de su arte.

Y también por contraposición, la independencia del artista, -otro de los valores supremos desde el siglo xix-, fue criticada en unos y alabada en otros. Mientras que en los artistas de vanguardia será prueba de su culpa en el divorcio entre arte y público - y de comportamiento antisocial-, en los artistas reconocidos y aceptados contribuirá a convertirlos en héroes. Eso sí, el término "independencia" en estos casos se entendió de manera muy restringida: como "independencia de" criterios artísticos, siempre en la dirección de rechazar el arte moderno. Independiente, también, fue aquel que se alejaba voluntariamente del éxito y decia no a los valores del mundo, tal como nos presenta, por ejemplo, Rafael Benet a Manolo Hugué: "[...]. su espíritu es realmente independiente - su independencia no está hecha de fraseologia, como la de tantos independientes oficiales que esconden con rugidos y manifiestos llenos de insolencia su mediocridad burguesa. Su independencia consubstancial le alejará de toda vanagloria” ${ }^{43}$.

No faltó tampoco un actitud tan falsa y gastada como la que resaltó el autodidactismo o la abierta rebelión de los artistas frente a las normas académicas; una paradoja si tenemos en cuenta que el arte español estaba tan dominado como de costumbre por los sectores artísticos más rígidos y conservadores.

Pero. domeñar la independencia del artista -fuera entendida ésta como fuera- estuvo entre las intenciones de quienes defendían un arte al servicio del nuevo Estado: los críticos e intelectuales falangistas -o próximos ideológicamente a ellos-, conscientes de que la libertad del artista

\footnotetext{
Juan Al whit / In EsiliatA. op. cit. pág. 41

Ratael Bi Ni 1. El Escultor Manolc Hugué. Barcelona. Libreria Editorial Argos. S.A. 1942. pág. 156
} 
suponia una amenaza para muchos de los valores sociales que se querían imponer. Por ello, van a demandarle sumisión: «Rinde tú también al espíritu, pintor, la soberbia creciente de la mano artesana. Reconoce, mal que te pese, realidades humanas de un orden superior al que puede alcanzar el brillante ejercicio de tus pinceles. Humilla tu cerviz para cuidar la sustancia admirable que debes ofrecer al afán de perfección de los demás hombres" ${ }^{44}$. Porque dentro de una ideología que fuerza a los individuos a integrarse en la norma y a negarse a sí mismos, que cree en la férrea jerarquización, en la autoridad autolegitimada y en un orden irrenunciable, en el que la "tarea más gozosa" - según José Antonio Primo de Rivera ${ }^{45}$ es la de obedecer, la de someterse, el artista no va a ser distinto al resto de los mortales. Su misión es poner su vida al servicio de Dios y de la gran empresa que es la Patria; un Dios, una empresa y una patria que le son mostradas desde la visión privilegiada del poder: «La Patria es para nosotros el fragmento más entrañable de este cosmos, una parte bien lograda en el universo, que quiere vivir y realizar la armonía divina, repitiendo rítmicamente la naturaleza del todo, en la gran traslación imperial hacia la unidad de destino, y en la rotación y revolución nacional de su conciencia irrenunciable.

Ni la Patria es indiferente al orden universal, ni las artes pueden ser indiferentes al orden de la Patria» ${ }^{46}$.

En ese sentido, y con una visión claramente maniquea se realza la sumisión frente a la rebeldia romántica convirtiéndose ahora en una cualidad del genio: "Velázquez, pues, representa para nosotros el tipo perfecto de sumisión, precisamente en estos años en que las inclinaciones de los artistas se sienten halagadas por ostensibles tipos de Rebelión uriversal, hacia la luciferina insumisión. El trastorno labora en nuestra época contra el propio genio, y así Picasso, el ibero substancial Pablo Picasso, que pudo haber sido el artista más completo de nuestro tiempo [...] se ha contentado con rebelarse consigo mismo, sin escuchar la voz de su conciencia de predestinado, para oír la voz del diablo que debe de haberle poseído solamente ab extra. [...] Velázquez, por el contrario, supo obedecer a Dios: supo sumirse en la obediencia no sólo de su Rey y Señor, sino que su genio, enorme por lo sencillo —su potente personalidad porque así a Dios le plugo - se halla saturado de un alto sentimiento de obediencia. $Y$

Luis Felipe Vivanco, "Humillación de la pintura", Vértice n 12, julio de 1938.

José Antonio Primo de Rivtra. “Discurso fundación del SEU», 21 de enero de 1935, recogido por Rafael Águila Tejerina, en op. cit., pág 210.

Rafael Sanchl z MazAS, "Confesión a los pintores". Arriba, 17 de marzo de 1940, págs. 1 y 5. 
es que Velázquez era un perfecto predestinado, y por lo tanto manso de corazón..." ${ }^{47}$.

Por otra parte, el individualismo, la libertad..., eran derechos que el artista había ido ganando a pulso como consecuencia y a partir de una fecha: 1789; año nefasto para la historia de la humanidad, según todos los fascismos europeos, porque la Revolución Francesa había significado la instauración del principio democrático, del gobierno de la razón y la relativización de unas verdades hasta entonces universalmente aceptadas. Habia que volver atrás, bucear en otras épocas, como proponía el principal teórico de Falange, Giménez Caballero, para poner en su sitio al artista, terminando de paso con la consideración social que gracias a la construcción de su propia historia venía tratando de lograr desde el Renacimiento: "Es un error creer que en las épocas de mayor esplendor artístico gozaron los artistas privilegios excepcionales como individuos. Por el contrario, se les tuvo como artesanos y operarios", porque hasta el siglo $x \mid x$ : «Los artistas formaban grupos profesionales, $y$ eran utilizados en empresas colectivas de tipo social y de sentido religioso. Pero desde que en el 800 surgió el problema de in arte libertas y comenzaron a estilarse "las exposiciones" para dar cauce a esa teórica libertad de los artistas, los artistas fueron perdiendo algo peor que la libertad: el arte mismo" ${ }^{48}$.

Porque para Giménez Caballero: "Fue una mentira del humanismo esa de que el artista podía vivir solo. La confirmación de tal mentira la dio el romarticismo con sus bohemios: extravagancia, miseria, sotabancos.

El artista ni puede, ni sabe, ni quiere vivir solo. Todo artista llevará dentro de si -siempre- al cofrade. En el doble sentido monacal y gremials, ${ }^{49}$.

Por ello, sugiere la integración del artista en una estructura corporativa: «El principio sindical tiende a recoger al artista de su posición marginal y encuadrarlo, ligarlo a la vida de la nación ${ }^{50}$. La propuesta no es más que el eco de la idea, tan cara a Falange, de que la restauración del orden de España, destruído por la República, sólo es posible dentro de una totalidad armónica: el Estado corporativo. Esto supone que la cooperación es el principio a imponer a la sociedad y sus miembros han de unirse a través de la función que desarrollan.

Rafael BENET, op. cit., 1946, pág. 40.

Ernesto Gimenez Caballeho. El Arte y el Estado, Madrid. Gráfica Universal, 1935, pág. 216 Ibidem. pág. 214.

lbídem. pág 218 
Desde luego, la aportación no es nueva - someter al artista a un gremio, a una estructura corporativa, a una institución, en definitiva, es un instrumento de control bastante antiguo- ni original, porque Giménez Caballero conocia bien las experiencias italiana y alemana, al respecto ${ }^{51}$.

Ese rechazo a la libertad del artista y ese afán de controlarlo, se explican por sí solos si tenemos en cuenta lo que el arte significaba para Falange; porque si bien, y tal y como indica Sheelagh Elwood, "el falangismo fue un fenómeno peculiarmente español, fruto de una determinada configuración de las circunstancias históricas y políticas de la España contemporánea» 52 , se hallaba claramente influido por el fascismo italiano y por el nacionalsocialismo alemán, regímenes para los que el arte era un elemento clave en la construcción del Estado - una concepción que tampoco es exclusiva de ambos-. En el caso de Alemania, por ejemplo, nos dice Peter Adam que: "Los nacionalsocialistas descubrieron que el arte no sólo podía ser vehiculo de mensajes políticos, sino que además era un medio perfecto para crear y manipular sueños y deseos. Podía programar las emociones de la población y dirigir su conducta» ${ }^{53}$.

En España quizá no se llegó tan lejos, pero si se deseó convertir el arte en arma política y obligar al artista a comprometerse, bajo la excusa de que ya no podía continuar al margen de la vida, de que ante la magnitud de los acontecimientos que habían vivido los españoles no tenía más remedio que implicarse: "Cuando España ha dado de si otra epopeya, no iban los pintores a estarse mano sobre mano sin inmortalizarla, o manchando de floreros y paisajitos kilómetros cuadrados de tela: por el contrario, van, como en los siglos anteriores, a dotar de grandes panoramas de hazaña inmortal a las generaciones que se educan en el sacrificio a las empresas altas, a retratar a los héroes, a sentir como humanistas la Humanidad y como poetas la Naturaleza, trono del alma ${ }^{54}$.

Y, así, el artista estaba destinado a desempeñar la doble tarea de combatiente y propagandista: «Desde hoy ese será el programa del artista:

En Espana y desde la Dirección General de Bellas Artes se llevó a cabo en 1940 un "Fichero de Artistas Españoles", que no era sino una forma de control de los creadores ya que es. taban obligados a aportar datos sobre si mismos y sobre su obra. Otra de las intervenciones es tatales fue la creación de un Sindicato de Artistas denominado Sindicato de Bellas Artes. dentro del Sindicato de Actividades Diversas que tambien en 1940. Seria traspasado al Sindicato de Profesiones Liberales.

Sheelagh Eiwonc. Prietas las tilas. Historia de la Falange Española. 1933-1983. Editoria! Crítica. S.A. Barcelona. 1984

Peter Alsam. El arte del Tercer Reich. Barcelona. Tusquets Editores. S.A. 1992. S.p pág. 8

Tomas Burtans. "Conjeturas sobre artes plásticas". El Español. n\% 10. 2 de enero de 1943. 
aprisionar rayos de luz y matar enemigos; aniquilar errores y sostener el ánimo de los navegantes ${ }^{55}$.

No obstante, esa doble tarea, no podía realizarse de cualquier manera, sino que había de seguir una dirección clara $-\mathrm{y}$ alejada de la realidad del país-: "Os pido simplemente que pintéis cara al nuevo sol, cara a la primavera y a la muerte, a la gracia, a la virtud, a la juventud, a la armonía, al orden exacto. No os pido cuadros patrióticos, ni mucho menos patrioteros y aduladores, sino cuadros que a la mente y a los sentidos traigan un reflejo del orden luminoso que queremos para la Patria enteras 56.

Sin embargo, los intelectuales y críticos falangistas no sólo trataron de perfilar el papel del artista como instrumento político -tarea, sepultada con la desaparición de los modelos italiano y alemán, en la que, a tenor de los resultados, no debieron de tener gran éxito- sino que, también, dirigieron sus esfuerzos a la creación de un arquetipo de artista hispánico que respondiera a lo que se consideraba la esencia del ser español; en razón a esa naturaleza se le va a exigir o suponer una serie de rasgos y comportamientos determinados. En este terreno si hay que decir que consiguieron difundir una imagen que iba a arraigar bien en la literatura artística. llegando casi sin variación hasta el final del franquismo.

El artista español se presentará bajo unas supuestas caracteristicas propias del pueblo al que pertenece: "el pueblo español es uno de los que presentan una estructura psicológica más complicada o por lo menos más difícilmente definible, por 10 mismo que está formada por múltiples razas y por culturas diversísimas; por eso desconcierta tan enormemente a los extranjeros. Así hemos visto en estos últimos años que si es uno de los pueblos en que puede prender una revolución destructora con mayor violencia, es, al propio tiempo, uno de los que ofrecen una mayor suma de elementos capaces de hacerla frente y finalmente de vencerla totalmente. [...] Elio es obra del fondo racial español sobre el cual se ha constituido la nación española. [...] ¿Qué características psicológicas tiene ese fondo étnico fundamental? Un autor, hablando de uno de los prototipos de la raza, ha escrito: "Noble per naturaleza, jefe nato, aunque lejos de ser buen organizador, insobornable por el lujo y la riqueza, amante fanático de la libertad, esclavo de su palabra, tenaz más que perseverante. [...].

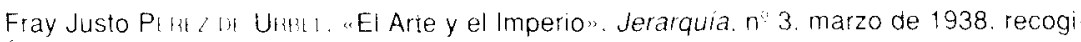
do por Ángel Llorente en su tesis doctoral, pág. 433.

Rafael SAnchl / MMAs. Op. cit. pág. 5 
Fondo racial, por tanto, el nuestro lleno de posibilidades y energias, pero que, falto de guía, puede llevar al más desenfrenado individualismo, y, en consecuencia, en último término, a la violencia y al desgarramiento" ${ }^{5}$.

Por eso, se aceptan y explican obras y artistas cuyo perfil, a primera vista, encajaría mal en los valores del régimen. Un ejemplo, puede ser Goya: «[...] Goya encarna un entrañable y violento españolismo; es, no un español, sino el español por antonomasia [...]. Y, lo mismo en su vida que en sus cuadros y que en sus dibujos y sus aguafuertes, ostenta todas las cualidades de la raza, con todos los defectos también. Le veremos aventurero, vehemente y apasionado, caballeresco, intolerante y terco. Es irascible, desigual de carácter, franco y leal. Todo le atrae y le exalta, pese a su escepticismo. "Truena contra la barbarie y la ignorancia y la injusticia le enciende en cólera". Cede el alma, y los pinceles, a la bondad y a la ternura. $Y$, sin dejar de advertir los errores de España, es patriota, gritándolo» 58.

La raza y sus cualidades tendrán constante presencia en todos los textos que pretendan elogiar en modo superlativo la obra de un artista. Decir que un artista lo es "de raza" -empleada esta palabra no en el sentido nacionalsocialista sino como alusión a linaje, a tradición-, supone el máximo tributo de admiración que puede rendírsele.

Manifestación de esa raza será el amor apasionado que ese tipo de artista "españolísimo" siente por su tierra. Como ejemplo, este texto de Ramón Faraldo sobre Benjamín Palencia:«Le solaza España, le arrebata España. Ello debe ser porque no ha ido a buscarla a los manaderos que se secan, en las glorias que se eclipsan, sino en eternidades más humildes e inmarcesibles: en sus artesanos, en sus labriegos [...] ${ }^{59}$.

El amor por la tierra española, conduce a otro ingrediente que jamás faltará en la caracterización del artista auténticamente hispano: el impacto que esa tierra produce en su obra. Así, los cuadros del Greco se explican gracias a una España que proporciona al pintor su espiritualidad; la pintura de Romero de Torres por el clasicismo y la poesía de Córdoba, la de Benjamin Palencia e Ignacio Zuloaga por su descubrimiento de Castilla. etc..., podrian ponerse numerosos ejemplos.

Ese debérselo todo a la tierra, en especial al paisaje y las gentes castellanas, que aportan al artista no sólo una influencia estética sino ética y

Santiago NADAL, "Lo ibérico y lo hispano en lo españoh", Destino n" 124. 2 de diciembre de 1939, pág. 2.

Ignacio of BFryes, op. cit., pág. 7.

Ramón Farialdo. op. cit. pág. 87 
moral, y esa búsqueda de la identidad española, tampoco es una ocurrencia original del franquismo, porque ya estaba en la Generación del 98 - siempre admirada y reinterpretada por los intelectuales del franquismo que convertirán en fetiche algunas de sus tesis-; basta recordar que Giménez Caballero se consideraba "nieto" del 98 y que Laín reconocía tres mitos históricos recibidos de ella: el del campo de Castilla, Don Quijote como héroe y arquetipo del nuevo hombre español y una España que en el futuro habría de combinar su carácter único con las demandas del mundo moderno. Aunque, sobre todo y quizá, una de las grandes aportaciones de la Generación fue la conciencia de que para encontrar la identidad perdida había que volver los ojos hacia la tradición.

Ahora, se hace una maniobra, en la que la catolicidad va a jugar un papel fundamental, para actualizarla y recuperarla, porque la tradición que trata de recobrarse es la de la grandeza imperial, e Imperio y Contrarreforma significarán la misma cosa.

En tal dirección se resaltará un pasado artístico glorioso muy concreto e inseparable de ese imperio y de esa religión: el de la España de los Austrias, el de artistas como el Greco o Velázquez, plenos de catolicismo y espiritualidad, de los que los artistas contemporáneos son herederos y, se supone, continuadores: "Hemos sido los españoles el pueblo que ha llamado mejor a Dios, en la Pintura, que tiene sentido propio desde el divino Morales, hasta el formidable grito entre todas las voces pictóricas que es el Greco.

Nuestro curso imperial, interrumpido cuando faltó la esencia hispana de catolicismo integral, y los regímenes quebraron por corrientes contrarias al sentido misional español, hallará en este resurgir glorioso la forma artística perdida entre ribetes extranjerizantes, y los pintores españoles seguirán como siempre señalando a la Pintura ventanas por donde mejor vern 60 .

$Y$ es que si, probablemente, no sólo los pintores, sino todos los artistas españoles mostraron "ventanas por donde mejor ver" pero seguramente "señalaron" pocas que siguieran el rumbo que se les habia indicado. Bajo visiones heterogéneas -en todo momento envueltas en pomposa retórica- limadas de asperezas para unos y cargadas de veneno para otros, adorados o vilipendiados, convertidos en estereotipo de una raza $y / 0$ instrumentalizados, ¿hasta qué punto calaron en ellos las ideas recibidas?

5o Manuel SANCHEZ CAMARGo, "La pintura de ayer, de hoy y de mañana", El Alcázar, 16-XI, 1939, pág. 2. 
¿Hasta dónde se sintieron cómodos con la imagen que de ellos se trazó? El tema merece, sin duda, toda una investigación pero lo cierto es que los artistas españoles, contemplados desde donde se contemplasen, no dejaron nunca de estar en el punto de mira de una sociedad que los necesitaba para legitimarse o para sobrevivir. 